CLINICAL STUDY

\title{
Decreased steroidogenic enzyme 17,20-lyase and increased 17-hydroxylase activities in type 2 diabetes mellitus
}

Hajime Ueshiba, Yusuke Shimizu, Naoki Hiroi, Fumiatsu Yakushiji, Masako Shimojo, Kumiko Tsuboi and Yukitaka Miyachi

First Department of Internal Medicine, Toho University School of Medicine, 6-11-1 Ohmori-nishi, Ohta-ku, Tokyo 143-O015, Japan

(Correspondence should be addressed to Hajime Ueshiba; Email: ueshiba@med.toho-u.ac.jp)

\begin{abstract}
Objective: To analyze activities of adrenal steroidogenic enzymes in type 2 diabetes mellitus, serum levels of 11 steroid hormones were measured simultaneously.

Subjects: We studied 130 patients with type 2 diabetes mellitus ( 74 men and 56 women between the ages of 40 and 69 years), whose blood glucose control had been poor (more than $10 \%$ in $\mathrm{HbA}_{1 \mathrm{c}}$ ). Age-matched normal subjects served as the control group.

Methods: Serum levels of steroid hormones (pregnenolone (Preg), progesterone (Prog), deoxycorticosterone (DOC), corticosterone (B), 17-hydroxypregnenolone (17-OH-Preg), 17-hydroxyprogesterone (17-OHP), 11-deoxycortisol (S), cortisol (F), dehydroepiandrosterone (DHEA) and $\Delta 4$-androstenedione $(\Delta 4 \mathrm{~A})$ ) were measured by HPLC/RIA methods. Fasting plasma glucose (FPG), HbA cc $_{c}$ ACTH, serum immunoreactive insulin (IRI) and DHEA sulfate (DHEA-S) were also measured. We analyzed product/precursor ratios to assess relative activities of adrenal steroidogenic enzymes.

Results: Serum levels of ACTH and F were high and DHEA and DHEA-S were low in both male and female patients under poor blood glucose control. Following 6-months treatment with diet only or with sulfonylurea, FPG and $\mathrm{HbA}_{1 \mathrm{c}}$ improved, and blood concentrations of ACTH and $\mathrm{F}$ decreased while DHEA and DHEA-S levels increased to within the normal range. DHEA/17-OH-Preg and $\Delta 4 \mathrm{~A} / 17-\mathrm{OHP}$ ratios, reflecting 17,20-lyase activity, were low before treatment and recovered to the normal range after treatment, and 17-OH-Preg/Preg and 17-OHP/Prog ratios, reflecting 17-hydroxylase activity, were high before treatment, and fell within the normal range after treatment. $3 \beta$ Hydroxysteroid dehydrogenase, 21-hydroxylase and 11 $\beta$-hydroxylase activities remained within the normal range both before and after treatment.

Conclusions: These data suggest that the decrease in DHEA and DHEA-S concentrations together with the high $\mathrm{F}$ levels that occur in patients with type 2 diabetes mellitus is associated with low 17,20-lyase and high 17-hydroxylase activity in the adrenal steroidogenic enzymes. High insulin concentrations may further lower DHEA and DHEA-S levels.
\end{abstract}

European Journal of Endocrinology 146 375-380

\section{Introduction}

Abnormalities of secretion and metabolism of many steroid hormones occur in diabetes mellitus. In poorly controlled insulin-dependent diabetes mellitus (IDDM), serum concentrations of dehydroepiandrosterone (DHEA) and its sulfate (DHEA-S) decrease (1) while plasma adrenocorticotropin (ACTH) and cortisol levels increase in non-insulin-dependent diabetes mellitus (NIDDM) (2). Low levels of DHEA and DHEA-S in type 2 diabetes mellitus are associated with hyperinsulinemia (3-7). Most studies have analyzed any one of glucocorticoid, mineralocorticoid or sex steroids. In the present study, to investigate activities of adrenal steroidogenic enzymes in type 2 diabetes mellitus we measured the serum levels of 11 steroid hormones simultaneously (8), and the analysis of product/precursor ratios was used to measure indirectly the relative activities of adrenal steroidogenic enzymes in type 2 diabetic patients with respect to the degree of blood glucose control.

\section{Materials and methods}

\section{Subjects}

The subjects were type 2 diabetic patients seen regularly at the outpatient clinic of Toho University Hospital. We chose 130 patients, whose blood glucose control had been poor (more than $10 \%$ in $\mathrm{HbA}_{1 \mathrm{c}}$ ). 
Their medication was managed by diet only or with sulfonylurea and patients under insulin therapy were excluded. The patient group consisted of 74 men and 56 women between the ages of 40 and 69 years. Age-matched normal subjects served as the control group. Informed consent was obtained from each subject before the study. Clinical characteristics of the patients and the normal controls are described in Table 1.

\section{Methods}

Blood samples were obtained from patients with type 2 diabetes mellitus and normal subjects between 0900 and $1000 \mathrm{~h}$ after an overnight fast. From patients with type 2 diabetes mellitus, blood samples were obtained before and 6 months after the treatment. Serum levels of 11 steroid hormones (pregnenolone (Preg), progesterone (Prog), deoxycorticosterone (DOC), corticosterone (B), 17-hydroxypregnenolone (17-OH-Preg), 17-hydroxyprogesterone (17-OHP), 11-deoxycortisol (S), cortisol (F), DHEA, DHEA-S, $\Delta 4$-androstenedione $(\Delta 4 \mathrm{~A}))$, plasma ACTH, fasting plasma glucose $(\mathrm{FPG}), \mathrm{HbA}_{1 \mathrm{c}}$, and serum immunoreactive insulin (IRI) were measured. Steroid hormones were determined by the previously reported HPLC/RIA methods (8) except DHEA-S, which was measured using an RIA kit (Mitsubisi Chemcal Co., Tokyo, Japan), FPG which was measured by the glucose oxidase method, $\mathrm{HbA}_{1 \mathrm{c}}$ which was measured by HPLC, and IRI and plasma ACTH which were measured by commercial kits (Daiichi, Tokyo, Japan).

Data are shown as means \pm S.D. Variables were compared by Bonferroni's analysis and $P$-values less than 0.05 were considered to indicate statistical significance.

\section{Results}

Compared with age-matched normal subjects, serum levels of DHEA and DHEA-S were low and those of $\mathrm{F}$ were high in both male and female patients with type 2 diabetes mellitus across the entire age range studied (Figs 1 and 2). Plasma levels of ACTH and IRI were high in all groups before the treatment (Table 1). Following 6-months treatment, FPG and $\mathrm{HbA}_{1 \mathrm{c}}$ improved and IRI decreased in most patients (Table 1 ). In parallel with the improvement in FPG and $\mathrm{HbA}_{1 \mathrm{c}}$, blood concentrations of ACTH and F decreased, and DHEA and DHEA-S levels increased to within the normal range in all the groups (Figs 1 and 2). Product/precursor ratios in serum steroids as an index of the relative activities of steroidogenic enzymes are shown in Fig. 3 and Tables 2-4. In male and female patients with type 2 diabetes mellitus, both DHEA/17-OH-Preg and $\Delta 4 \mathrm{~A} / 17-\mathrm{OHP}$ ratios, reflecting 17,20-lyase activity, were low before treatment and recovered to the normal range after treatment (Fig. 3). Both 17-OHPreg/Preg and 17-OHP/Prog ratios, reflecting 17-hydroxylase activity, were high in diabetic patients before treatment, and fell within the normal range

Table 1 Clinical characteristics of type 2 diabetic patients before and after treatment and in age-matched normal subjects.

\begin{tabular}{|c|c|c|c|c|c|c|}
\hline & Number & BMI $\left(\mathrm{kg} / \mathrm{m}^{2}\right)$ & FPG $(\mathrm{mmol} / \mathrm{l})$ & $\mathrm{HbA}_{1 \mathrm{c}}(\%)$ & IRI (pmol/I) & ACTH (pmol/l) \\
\hline \multicolumn{7}{|l|}{ Male 40 years } \\
\hline Before treatment & 22 & $25.1 \pm 1.5^{\star}$ & $10.2 \pm 0.9^{*}$ & $11.6 \pm 1.2^{\star}$ & $68.9 \pm 23.7^{*}$ & $7.9 \pm 2.0^{*}$ \\
\hline After treatment & 22 & $24.2 \pm 1.2^{\star \star}$ & $6.2 \pm 0.8^{* *}$ & $7.2 \pm 0.6^{\star \star}$ & $53.8 \pm 11.5^{\star \star}$ & $5.5 \pm 1.8^{\star *}$ \\
\hline Normal & 20 & $22.3 \pm 0.9$ & $5.2 \pm 0.3$ & $5.2 \pm 0.3$ & $40.9 \pm 12.2$ & $4.8 \pm 1.1$ \\
\hline \multicolumn{7}{|l|}{ Male 50 years } \\
\hline Before treatment & 29 & $24.4 \pm 1.2^{*}$ & $9.6 \pm 1.0^{*}$ & $11.7 \pm 1.2^{*}$ & $72.5 \pm 23.0^{*}$ & $8.1 \pm 2.0^{*}$ \\
\hline After treatment & 29 & $23.6 \pm 1.1$ & $5.9 \pm 0.8^{\star *}$ & $6.8 \pm 0.6^{\star \star}$ & $49.5 \pm 9.3^{\star *}$ & $6.9 \pm 2.1^{\star *}$ \\
\hline Normal & 25 & $22.7 \pm 0.9$ & $5.2 \pm 0.3$ & $5.1 \pm 0.3$ & $42.3 \pm 10.0$ & $5.7 \pm 0.9$ \\
\hline \multicolumn{7}{|l|}{ Male 60 years } \\
\hline Before treatment & 23 & $25.0 \pm 1.5^{\star}$ & $9.8 \pm 1.1^{*}$ & $11.4 \pm 1.1^{*}$ & $75.3 \pm 30.9^{*}$ & $7.3 \pm 1.8^{*}$ \\
\hline After treatment & 23 & $24.1 \pm 1.2$ & $5.6 \pm 0.8^{\star \star}$ & $6.7 \pm 0.6^{\star \star}$ & $52.4 \pm 7.9^{* *}$ & $6.2 \pm 1.7^{\star *}$ \\
\hline Normal & 20 & $22.4 \pm 0.7$ & $5.0 \pm 0.4$ & $5.2 \pm 0.2$ & $40.2 \pm 7.9$ & $5.3 \pm 1.1$ \\
\hline \multicolumn{7}{|l|}{ Female 40 years } \\
\hline Before treatment & 17 & $24.4 \pm 2.3^{*}$ & $9.6 \pm 0.9^{*}$ & $12.0 \pm 1.1^{*}$ & $54.5 \pm 17.2^{*}$ & $7.7 \pm 2.0^{\star}$ \\
\hline After treatment & 17 & $23.8 \pm 1.4$ & $5.5 \pm 0.6^{\star \star}$ & $7.0 \pm 0.6^{\star \star}$ & $56.0 \pm 6.5^{\star *}$ & $5.5 \pm 1.4^{\star \star}$ \\
\hline Normal & 15 & $21.7 \pm 1.5$ & $5.2 \pm 0.4$ & $5.1 \pm 0.2$ & $44.5 \pm 9.3$ & $5.3 \pm 1.3$ \\
\hline \multicolumn{7}{|l|}{ Female 50 years } \\
\hline Before treatment & 23 & $23.8 \pm 1.0^{*}$ & $9.2 \pm 0.9^{*}$ & $11.6 \pm 0.8^{\star}$ & $65.3 \pm 26.5^{*}$ & $7.9 \pm 2.2^{*}$ \\
\hline After treatment & 23 & $23.3 \pm 0.6$ & $5.2 \pm 0.3^{\star \star}$ & $6.7 \pm 0.4^{\star \star}$ & $46.6 \pm 8.6^{\star \star}$ & $6.0 \pm 1.3^{\star \star}$ \\
\hline Normal & 20 & $22.6 \pm 0.7$ & $5.1 \pm 0.4$ & $5.1 \pm 0.3$ & $38.7 \pm 7.2$ & $5.7 \pm 1.5$ \\
\hline \multicolumn{7}{|l|}{ Female 60 years } \\
\hline Before treatment & 16 & $24.2 \pm 1.1^{*}$ & $9.7 \pm 1.1^{*}$ & $11.9 \pm 1.2^{*}$ & $59.6 \pm 21.5^{\star}$ & $8.4 \pm 2.2^{*}$ \\
\hline After treatment & 16 & $23.3 \pm 0.9^{\star *}$ & $5.4 \pm 0.5^{\star \star}$ & $6.8 \pm 0.5^{\star \star}$ & $48.8 \pm 10.8^{\star *}$ & $7.2 \pm 1.4$ \\
\hline Normal & 15 & $22.7 \pm 0.6$ & $5.2 \pm 0.3$ & $5.3 \pm 0.3$ & $38.0 \pm 6.5$ & $5.5 \pm 1.3$ \\
\hline
\end{tabular}

${ }^{\star} P<0.05$ vs normal, ${ }^{\star \star} P<0.05$ vs before treatment. 

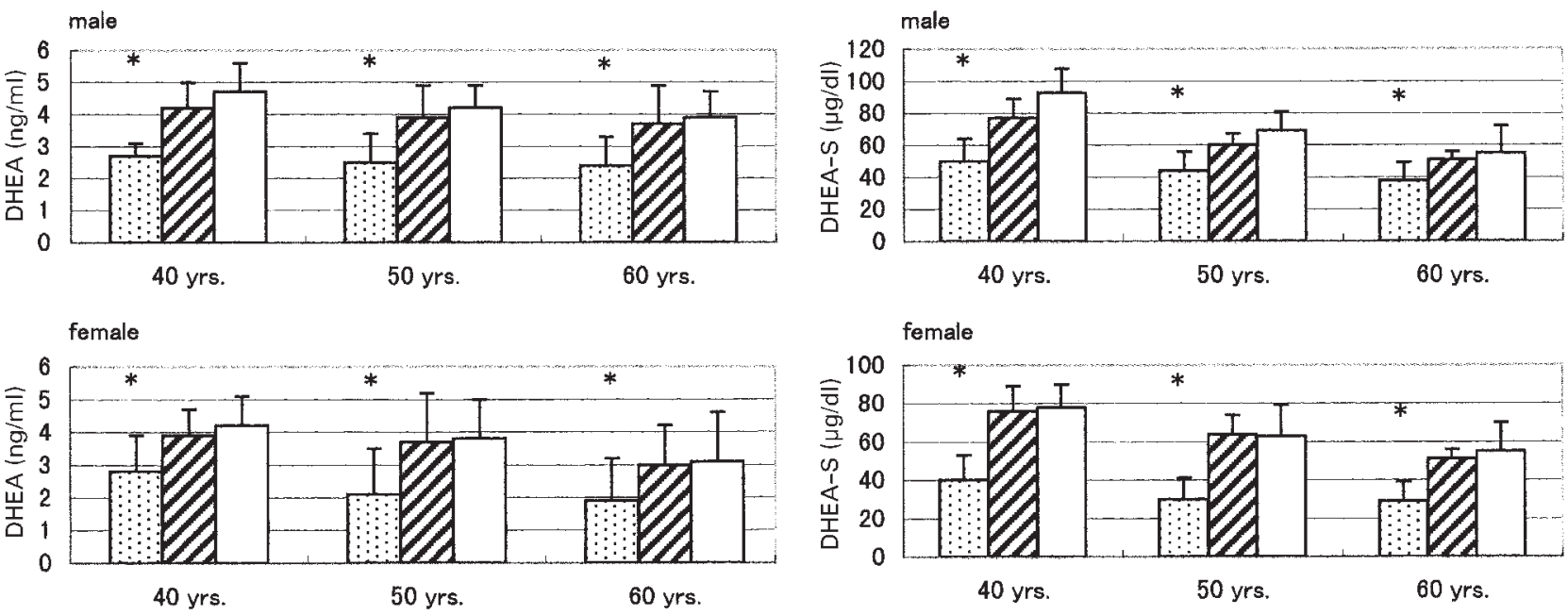

Figure 1 Serum DHEA and DHEA-S levels in male and female type 2 diabetic patients before (stippled bars) and after (hatched bars) treatment and in age-matched normal subjects (open bars). ${ }^{*} P<0.05$ compared with values after treatment and with normal values.

after treatment (Fig. 3). 3ß-Hydroxysteroid dehydrogenase activity assessed by Prog/Preg, 17-OHP/ 17-OH-Preg, and $\triangle 4$ A/DHEA ratios (Table 2), 21-hydroxylase activity assessed by DOC/Prog and S/17-OHP ratios (Table 3) and 11ß-hydroxylase activity assessed by $\mathrm{B} / \mathrm{DOC}$ and $\mathrm{F} / \mathrm{S}$ ratios (Table 4) remained within the normal ranges both before and after treatment.

\section{Discussion}

We have examined serum steroid hormone profiles in patients with type 2 diabetes mellitus under poor
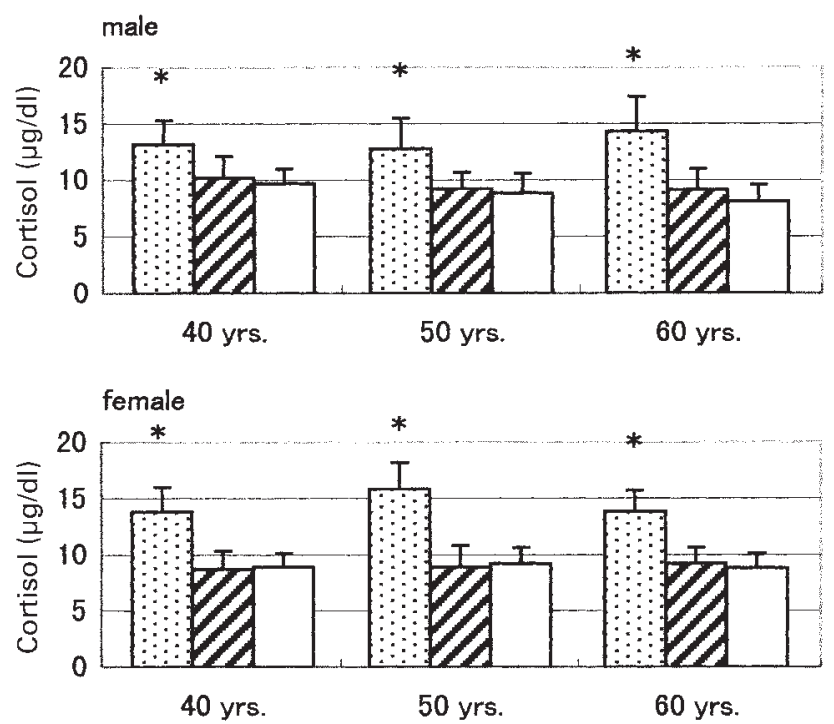

Figure 2 Serum cortisol levels in male and female type 2 diabetic patients before (stippled bars) and after (hatched bars) treatment and in age-matched normal subjects (open bars). ${ }^{*} P<0.05 \mathrm{com}-$ pared with values after treatment and with normal values. therapeutic control stratified by three decades in age. We have also assessed the enzymatic activities by analysis of product/precursor ratios of C-21 and C-19 steroid hormones in the steroidogenic pathway to determine how their ratios may change with the control of type 2 diabetes mellitus. As most previous studies were mainly concerned with steroid hormones in one of three steroidogenic pathways - to either cortisol,

Table $23 \beta$-HSD activities assessed by Prog/Preg, $17-\mathrm{OHP} / 17-\mathrm{OH}$-Preg and $\triangle 4 \mathrm{~A} / \mathrm{DHEA}$ ratios in male and female type 2 diabetic patients before and after treatment and in agematched normal subjects.

\begin{tabular}{|c|c|c|c|}
\hline & Prog/Preg & 17-OHP/17-OH-Preg & $\triangle 4 \mathrm{~A} / \mathrm{DHEA}$ \\
\hline \multicolumn{4}{|c|}{ Male 40 years } \\
\hline Before & $0.22 \pm 0.09$ & $1.08 \pm 0.25$ & $0.40 \pm 0.18^{\star}$ \\
\hline After & $0.25 \pm 0.10$ & $0.99 \pm 0.31$ & $0.26 \pm 0.19$ \\
\hline Normal & $0.23 \pm 0.08$ & $0.95 \pm 0.28$ & $0.24 \pm 0.06$ \\
\hline \multicolumn{4}{|c|}{ Male 50 years } \\
\hline Before & $0.27 \pm 0.11$ & $1.21 \pm 0.19$ & $0.26 \pm 0.13$ \\
\hline After & $0.26 \pm 0.12$ & $1.03 \pm 0.28$ & $0.25 \pm 0.18$ \\
\hline Normal & $0.15 \pm 0.10$ & $0.98 \pm 0.31$ & $0.26 \pm 0.10$ \\
\hline \multicolumn{4}{|c|}{ Male 60 years } \\
\hline Before & $0.24 \pm 0.13$ & $1.24 \pm 0.21$ & $0.46 \pm 0.14^{*}$ \\
\hline After & $0.25 \pm 0.19$ & $0.98 \pm 0.29$ & $0.29 \pm 0.17$ \\
\hline Normal & $0.21 \pm 0.12$ & $0.96 \pm 0.32$ & $0.26 \pm 0.13$ \\
\hline \multicolumn{4}{|c|}{ Female 40 years } \\
\hline Before & $0.55 \pm 0.18$ & $1.30 \pm 0.14$ & $0.35 \pm 0.12$ \\
\hline After & $0.59 \pm 0.13$ & $1.13 \pm 0.19$ & $0.27 \pm 0.13$ \\
\hline Normal & $0.51 \pm 0.14$ & $1.14 \pm 0.21$ & $0.26 \pm 0.15$ \\
\hline \multicolumn{4}{|c|}{ Female 50 years } \\
\hline Before & $0.56 \pm 0.21$ & $1.42 \pm 0.18$ & $0.44 \pm 0.14^{*}$ \\
\hline After & $0.57 \pm 0.18$ & $1.18 \pm 0.15$ & $0.25 \pm 0.18$ \\
\hline Normal & $0.51 \pm 0.15$ & $1.36 \pm 0.19$ & $0.26 \pm 0.13$ \\
\hline \multicolumn{4}{|c|}{ Female 60 years } \\
\hline Before & $0.48 \pm 0.18$ & $1.22 \pm 0.14$ & $0.45 \pm 0.19^{\star}$ \\
\hline After & $0.39 \pm 0.14$ & $1.01 \pm 0.13$ & $0.29 \pm 0.11$ \\
\hline Normal & $0.42 \pm 0.13$ & $1.12 \pm 0.19$ & $0.27 \pm 0.12$ \\
\hline
\end{tabular}

${ }^{*} P<0.05$ vs normal value and after treatment. $3 \beta$-HSD, $3 \beta$-hydroxysteroid dehydrogenase. 

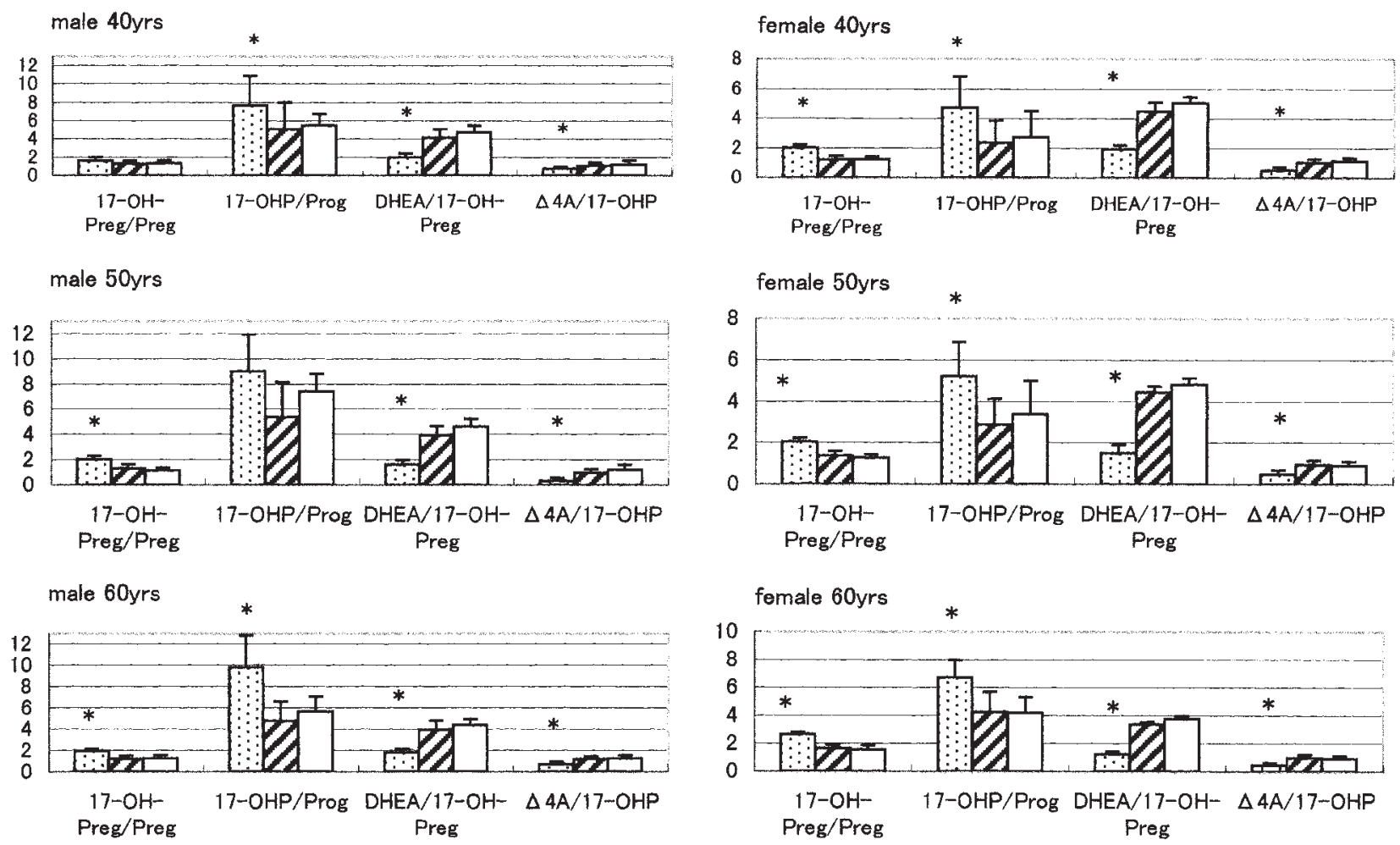

Fig. 3 17-Hydroxylase activities assessed by 17-OH-Preg/Preg and 17-OHP/Prog ratios and 17-20-lyase activities assessed by DHEA/17-OH-Preg and $\Delta 4 \mathrm{~A} / 17-\mathrm{OHP}$ ratios in male and female type 2 diabetic patients before (stippled bars) and after (hatched bars) treatment and in age-matched normal subjects (open bars). ${ }^{*} P<0.05$ compared with values after treatment and with normal values.

Table 3 21-Hydroxylase activities assessed by DOC/Prog and $\mathrm{S} / 17-\mathrm{OHP}$ ratios in male and female type 2 diabetic patients before and after treatment and in age-matched normal subjects.

\begin{tabular}{lll}
\hline & DOC/Prog & S/17-OHP \\
\hline Male 40 years & & \\
Before & $0.29 \pm 0.18$ & $0.88 \pm 0.24$ \\
After & $0.32 \pm 0.13$ & $0.85 \pm 0.31$ \\
$\quad$ Normal & $0.35 \pm 0.14$ & $0.81 \pm 0.23$ \\
Male 50 years & & \\
Before & $0.32 \pm 0.21^{*}$ & $0.71 \pm 0.23$ \\
After & $0.38 \pm 0.18$ & $0.90 \pm 0.28$ \\
Normal & $0.56 \pm 0.19$ & $0.97 \pm 0.27$ \\
Male 60 years & & \\
Before & $0.28 \pm 0.12$ & $0.85 \pm 0.21$ \\
After & $0.26 \pm 0.14$ & $0.96 \pm 0.24$ \\
Normal & $0.37 \pm 0.18$ & $0.92 \pm 0.18$ \\
Female 40 years & & \\
Before & $0.13 \pm 0.09$ & $0.83 \pm 0.19$ \\
After & $0.14 \pm 0.11$ & $0.91 \pm 0.18$ \\
Normal & $0.17 \pm 0.12$ & $0.86 \pm 0.15$ \\
Female 50 years & & \\
Before & $0.15 \pm 0.10$ & $0.75 \pm 0.21$ \\
After & $0.19 \pm 0.13$ & $0.95 \pm 0.14$ \\
Normal & $0.19 \pm 0.14$ & $0.81 \pm 0.19$ \\
Female 60 years & & \\
Before & $0.18 \pm 0.09$ & $0.73 \pm 0.19$ \\
After & $0.28 \pm 0.12$ & $1.02 \pm 0.16$ \\
Normal & $0.23 \pm 0.14$ & $0.91 \pm 0.21$ \\
\hline
\end{tabular}

${ }^{*} P<0.05$ vs normal.
Table $411 \beta$-Hydroxylase activities assessed by B/DOC and F/S ratios in male and female type 2 diabetic patients before and after treatment and in age-matched normal subjects.

\begin{tabular}{llr}
\hline & B/DOC & \multicolumn{1}{c}{ F/S } \\
\hline Male 40 years & & \\
$\quad$ Before & $25.9 \pm 10.3$ & $10.2 \pm 2.9$ \\
$\quad$ After & $22.2 \pm 10.9$ & $11.7 \pm 2.4$ \\
$\quad$ Normal & $25.3 \pm 9.7$ & $12.7 \pm 2.1$ \\
Male 50 years & & \\
$\quad$ Before & $21.9 \pm 9.4$ & $9.5 \pm 3.1$ \\
$\quad$ After & $18.8 \pm 8.8$ & $10.0 \pm 2.1$ \\
$\quad$ Normal & $20.8 \pm 9.2$ & $10.1 \pm 2.4$ \\
Male 60 years & & \\
$\quad$ Before & $27.9 \pm 8.8$ & $10.1 \pm 2.7$ \\
After & $25.4 \pm 9.4$ & $10.3 \pm 1.9$ \\
$\quad$ Normal & $23.0 \pm 7.9$ & $10.2 \pm 2.1$ \\
Female 40 years & & \\
$\quad$ Before & $26.7 \pm 7.4$ & $8.8 \pm 1.9$ \\
After & $25.1 \pm 9.8$ & $9.7 \pm 2.4$ \\
$\quad$ Normal & $24.6 \pm 8.3$ & $10.8 \pm 2.3$ \\
Female 50 years & & \\
$\quad$ Before & $23.1 \pm 8.2$ & $10.6 \pm 2.1$ \\
After & $21.8 \pm 7.8$ & $9.5 \pm 1.4$ \\
$\quad$ Normal & $22.2 \pm 8.8$ & $10.4 \pm 1.6$ \\
Female 60 years & & \\
$\quad$ Before & $24.4 \pm 6.9$ & $10.0 \pm 1.8$ \\
After & $21.0 \pm 8.2$ & $10.1 \pm 2.4$ \\
Normal & $22.6 \pm 7.9$ & $10.5 \pm 2.1$ \\
\hline$\quad$ & &
\end{tabular}


aldosterone or DHEA, this is the first report describing simultaneous analyses of steroid hormones of three different steroidogenic pathways in type 2 diabetes mellitus. In this study we demonstrated that serum DHEA and DHEA-S levels decreased markedly under poor control of type 2 diabetes mellitus and increased to agematched normal values with the improvement of FPG and $\mathrm{HbA}_{1 \mathrm{c}}$ after 6 months treatment with diet and/or sulfonylurea. Barrett-Connor showed that DHEA and DHEA-S levels were also low in patients with noninsulin dependent diabetes mellitus (9), but she did not measure changes in these steroid hormones after treatment. Markedly reduced levels of DHEA and DHEA-S in type 2 diabetes mellitus under poor therapeutic control, with slightly increased plasma IRI are consistent with an association between DHEA synthesis and/or metabolism and insulin. Nestler and colleagues showed that insulin reduces serum DHEA and DHEA-S in men either by inhibiting their production or by increasing the metabolic clearance rate of DHEA $(10,11)$. The metabolic clearance rate of DHEA is reported to be increased two- to fivefold in obesity and in the insulin-resistant, hyperinsulinemic state (11). The infusion of high doses of insulin reduces serum DHEA levels, suggesting the involvement of the inhibition of adrenal 17,20-lyase activity. Administration of metformin, which inhibits hepatic glucose production and enhances peripheral tissue sensitivity to insulin, to healthy normal weight men and to obese men with hypertension but without diabetes mellitus decreased serum insulin levels and increased serum DHEA-S levels in obese men with hypertension and in healthy controls (12). Our data showing that both the DHEA/17-OH-Preg and the $\Delta 4 \mathrm{~A} / 17-\mathrm{OHP}$ ratios, reflecting 17,20-lyase activity, were low in patients with type 2 diabetes mellitus before treatment and recovered to the normal range after treatment are consistent with these reports. However, Yamauchi et al. reported that serum DHEA and DHEA-S levels are low even in patients with impaired glucose tolerance and low insulin response (13), and therefore the decrease in serum DHEA levels may not arise exclusively from the hyperinsulinemic state. Hyperglycemia may reduce 17,20-lyase activity and consequently serum DHEA may decrease. The improvement in plasma glucose control parallels the recovery of 17,20-lyase activity. When micronized DHEA $(50 \mathrm{mg})$ was administered to healthy postmenopausal women, DHEA significantly enhanced insulin sensitivity over the placebo, attenuating the age-related decline in glucose tolerance (14). We found that both F and ACTH levels were high in patients with type 2 diabetes mellitus and they returned to normal with improvement in glycemic control. As both the 17-OH-Preg/Preg and 17-OHP/Prog ratios, reflecting 17-hydroxylase activity, were high in most patients with type 2 diabetes mellitus, the increase in this enzyme may produce the increased $\mathrm{F}$ secretion. The increase in ACTH and F was reported to correlate positively with the duration of diabetes mellitus (15) and with the degree of complications such as neuropathy (16) and retinopathy (17). It seems likely that hyperglycemia in patients with type 2 diabetes mellitus is also responsible for the relative hypersecretion of ACTH and cortisol due to a hyperactive hypothalamic-pituitary-adrenal (HPA) axis. It has been suggested that patients with type 2 diabetes mellitus have abnormalities in the HPA axis $(2,15)$, especially abnormalities in negative feedback regulation by cortisol at the pituitary level due to some metabolic disorders (3). Recent studies show the relationship between the HPA axis and insulin resistance syndrome $(18,19)$. Obese patients with visceral adiposity have a hyperactive HPA axis. In this study some patients were obese; however the body mass index in most patients did not change significantly before and after treatment; therefore the relationship between the HPA axis and visceral adiposity is unclear.

In conclusion, the data collectively suggest that the decrease in DHEA and DHEA-S concentrations together with the high IRI and $\mathrm{F}$ levels that occur in patients with type 2 diabetes mellitus is associated with low 17,20-lyase and high 17-hydroxylase activities in the steroidogenic enzymes. High insulin concentrations may further lower DHEA and DHEA-S concentrations.

\section{References}

1 Couch RM. Dissociation of cortisol and adrenal androgen secretion in poorly controlled insulin-dependent diabetes mellitus. Acta Endocrinologica 1992127 115-117.

2 Hashimoto K, Nishioka T, Takao T \& Numata Y. Low plasma corticotropin-releasing hormone $(\mathrm{CRH})$ levels in patients with non-insulin dependent diabetes mellitus (NIDDM). Endocrine Journal $1993 \mathbf{4 0} 705-709$.

3 Nesler JE, Usiskin KS, Barlascini CO, Welty DF, Clore JN \& Blackard WG. Supression of serum dehydroepiandrosterone sulfate levels by insulin: an evaluation of possible mechanisms. Journal of Clinical Endocrinology and Metabolism 198969 1040-1046.

4 Diamond MP, Grainger DA, Laudano AJ, Starick-Zych K \& DeFronzo RA. Effect of acute physiological elevations of insulin on circulating androgen levels in nonobese women. Journal of Clinical Endocrinology and Metabolism 199172 883-887.

5 Hubert GD, Schriock ED, Givens JR \& Buster JE. Suppression of circulating $\Delta 4$-androstenedione and dehydroepiandrosterone sulfate during oral glucose tolerance in normal females. Journal of Clinical Endocrinology and Metabolism 199173 781-784.

6 Smith S, Ravnikar VA \& Barbieri RL. Androgen and insulin response to an oral glucose challenge in hyperandrogenic women. Fertility and Sterility $1987 \mathbf{4 8} 72-77$.

7 Schriock ED, Buffington CK, Hubert GD, Kurtz BR, Kitabchi AE, Buster JE et al. Divergent correlation of circulating dehydroepiandrosterone sulfate and testosterone with insulin levels and insulin receptor binding. Journal of Clinical Endocrinology and Metabolism 198866 1329-1331.

8 Ueshiba H, Segawa M, Hayashi T, Miyachi Y \& Irie M. Serum steroid hormones in patients with Cushing's syndrome determined by a new HPLC/RIA method. Clinical Chemistry 199137 1329-1333.

9 Barrett-Connor E. Lower endogenous androgen levels and dyslipidemia in men with non-insulin dependent diabetes mellitus. Annals of Internal Medicine 1992117 807-811. 
10 Nestler JE, McClanahan MA, Clore JN \& Blackard WG. Insulin inhibits adrenal 17,20-lyase activity in men. Journal of Clinical Endocrinology and Metabolism $199274362-367$.

11 Nestler JE. Regulation of human dehydroepiandrosterone metabolism by insulin. Annals of the New York Academy of Sciences $199577473-81$.

12 Nestler JE, Beer NA, Jakubowicz DJ \& Beer RM. Effects of a reduction in circulating insulin by metformin on serum dehydroepiandrosterone sulfate in nondiabetic men. Journal of Clinical Endocrinology and Metabolism 199478 549-554.

13 Yamauchi A, Takei I, Nakamoto S, Ohashi N, Kitamura Y, Tokui $\mathrm{M}$ et al. Hyperglycemia decreased dehydroepiandrosterone in Japanese male with impaired glucose tolerance and low insulin response. Endocrine Journal 199643 285-290.

14 Bates GW Jr, Egerman RS, Unstot ES, Buster JE \& Casson PR. Dehydroepiandrosterone attenuated study-induced declines in insulin sensitivity in postmenopausal women. Annals of the New York Academy of Sciences $1995 \mathbf{7 7 4} 291-293$.

15 Roy M, Collier B \& Roy A. Hypothalamic-pituitary-adrenal dysregulation among diabetic outpatients. Psychiatry 199031 31-37.

16 Tsigos C, Young RJ \& White A. Diabetic neuropathy is associated with increased activity of the hypothalamic-pituitary-adrenal axis. Journal of Clinical Endocrinology and Metabolism $1993 \mathbf{7 6}$ 554-558.

17 Lu J, Li J, Pan C, Lu S, Ma S \& Gao A. Changes of pituitaryadrenal functions in diabetics and their response to aminogluthetimide. Chinese Medical Journal 1988101 587-590.

18 Vicennati V \& Pasquali R. Abnormalities of the hypothalamicpituitary-adrenal axis in nondepressed women with abdominal obesity and relations with insulin resistance: evidence for a central and a peripheral alteration. Journal of Clinical Endocrinology and Metabolism 2000 85 4093-4098.

19 Ljung T, Holm G, Friberg P, Andersson B, Bengtsson BA, Svensson J, Dallman M, McEwen B \& Bjorntorp P. The activity of the hypothalamic-pituitary-adrenal axis and the sympathetic nervous system in relation to waist/hip circumference ratio in men. Obesity Research 20008 487-495.

Received 20 June 2001

Accepted 31 October 2001 